\title{
Evaluation of Driver Stress Using Motor-vehicle Driving Simulator
}

\author{
Mitsuo Deguchi Non-member (University of Toyama, m042174@ems.toyama-u.ac.jp) \\ Junichi Wakasugi Non-member (University of Toyama, m0570353@ems.u-toyama.ac.jp) \\ Tatsuya Ikegami Non-mamber (DENSO Co., TATSUYA_IKEGAMI@denso.co.jp) \\ Shinji Nanba Non-mamber (DENSO Co., snanba@rlab.denso.co.jp) \\ Masaki Yamaguchi Senior Member （University of Toyama, yamag@eng.u-toyama.ac.jp)
}

Keywords : amylase, saliva, stress, motor-vehicle, simulator, sympathetic nervous system

In order to improve safety in motor-vehicle driving, many studies of a monitoring method for driver stress or fatigue have been investigated. Drivers may undergo high stress with abrupt steering, emergency brake operation, obstacles on the roadway or abrupt changes in the curvature of the road. However, investigations of these operations can not be conducted under actual driving conditions, as they could lead to real accidents. As a result of significantly improved interior comfort and operational performance of motor-vehicles, drivers do not experience severe stress over several hours of driving. It is not easy to evaluate a driving stress over a long-term period. Furthermore, the physical measurement methods used for psycological measurements can not offer an index used easily and quickly at any time because they have some limitations in the measurement conditions.

This paper proposes a method for evaluating driver stress using a motor-vehicle driving simulator and a biomarker as an index of stress. Software has been developed, which can deliberately control driving tasks, in addition to analyzing driving information, such as frequency of the use of accelerator and/or brakes and the degree of deviation from the driving course.

Sympathetic nervous activity was noninvasively evaluated using a hand-held monitor of salivary amylase activity $(110 \times 100$ $\times 40 \mathrm{~mm}^{3}, 350 \mathrm{~g}$ ), which biochemically measured a biomarker every few minutes. This monitor could analyze salivary amylase activities by collecting only $30 \mu \mathrm{l}$ saliva on a test-strip, taking just $30 \mathrm{~s}$. The color changes in the reagent paper takes only a further $30 \mathrm{~s}$, just 1 minute per measurement in total.

Using healthy 20 female adults, the appropriateness of the proposed method was evaluated in vivo. The study protocol was approved by the Ethical Committee of University of Toyama. The study protocol was fully explained to all of the subjects, both verbally and in writing, specifically focusing on the purpose of the study, the precise procedures that would be used and any possible adverse events. Signed informed consent was obtained from each subject who enrolled in the study.

The experimental results showed that driving stress might be caused to the drivers in only 20 minutes by adding more severe driving tasks than normally experienced by the subjects without endangering them. Furthermore, the increasing rate of salivary amylase activity caused by the simulated driving stress could be categorized into two groups, independent of frequency of the subjects' driving in daily life. The results demonstrated a possibility that the incremental rate in sympathetic nervous activity could be related to the stress resistance or characteristics of the indivisuals.

Furthermore, the result indicates that frequent measurements of sympathetic nervous activity were possible without putting the subjects under restraint by using a biomarker as the index.

It is considered that this accelerated method for evaluating driver stress can be applied to the development of comfortable interiors of automobiles or to better driving performance, in addition to avoiding dangers in driving caused by human errors.

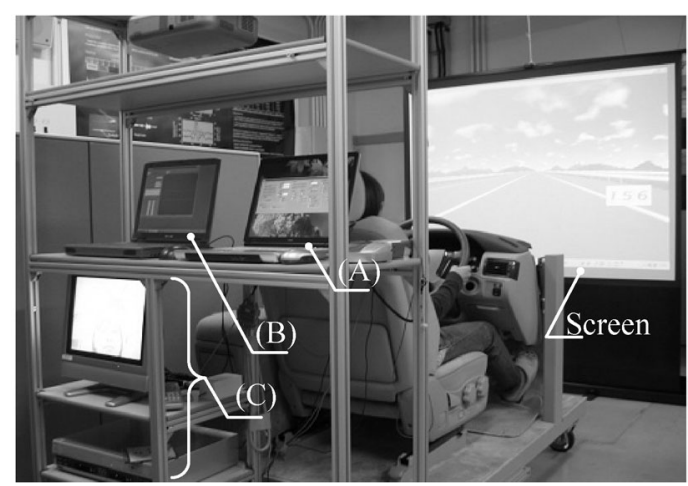

(a) External view of a motor-vehicle driving simulator

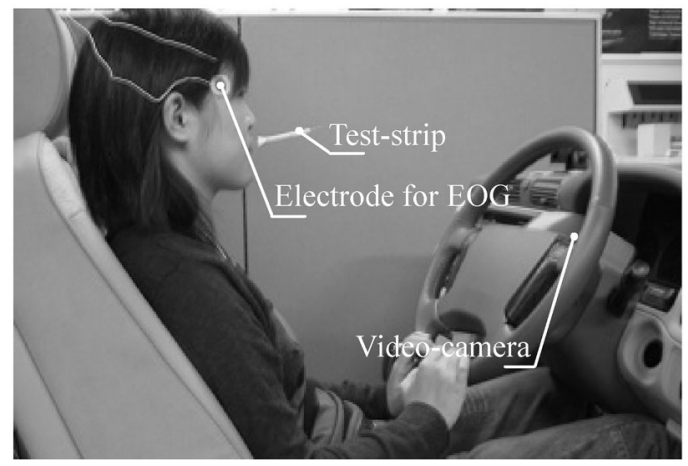

(b) Collecting of saliva

Fig. 1. External view of a fabricated motor-vehicle driving simulator and evaluation of driver stress; (A) computer for control, (B) computer for measurement, (C) video-camera and recorder. 


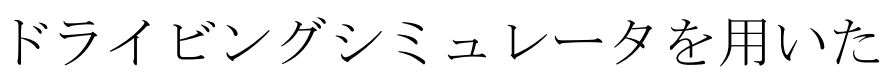

運転ストレスの試験方法

$\begin{array}{llll}\text { 非会員 出口 } & \text { 満生* } & \text { 非会員 若杉 純一* } \\ \text { 非会員 池上 } & \text { 達也** } & \text { 非会員 難波 晋治** } \\ \text { 上級会員 山口 } & \text { 昌樹* } & & \end{array}$

\section{Evaluation of Driver Stress Using Motor-vehicle Driving Simulator}

Mitsuo Deguchi*, Non-member, Junichi Wakasugi*, Non-member,

Tatsuya Ikegami**, Non-member, Shinji Nanba**, Non-member, Masaki Yamaguchi*, Senior Member

This paper proposes a method for evaluating driver stress using a motor-vehicle driving simulator and a biomarker as an index of stress. Software has been developed, which can deliberately control driving tasks, in addition to analyzing driving information, such as frequency of the use of accelerator and/or brakes and the degree of deviation from the driving course. Sympathetic nervous activity was noninvasively evaluated using a hand-held monitor of salivary amylase activity, which chemically measured a biomarker every few minutes. Using healthy 20 female adults, the appropriateness of the proposed method was evaluated in vivo. The experimental results showed that the driving stress might be caused to the drivers in only 20 minutes by adding more severe driving tasks than normally experienced by the subjects without endangering them. Furthermore, the result indicate that frequent measurements of sympathetic nervous activity were possible without putting the subjects under restraint by using salivary amylase activity as the index.

キーワード : アミラーゼ, 唾液, ストレス, 自動車, シミュレータ, 交感神経系

Keywords : amylase, saliva, stress, motor-vehicle, simulator, sympathetic nervous system

\section{1. まえがき}

超高齢化社会で若年労働力が減少していく社会環境にお いて，安全・安心な社会を実現していくためには，人的エ ラーを予知し，どこまで減らせるかが重要である。そのひ とつとして，自動車運転時のストレスや疲労をモニタリン グしようという試みが盛んに研究されている(1) (3)。

人は, 感覚器で感知された刺激が脳に伝達され, 記憶や 情動に作用し，ストレスを感じている。自動車運転におい ては, 急ハンドル, 急ブレーキの操作, 道路上の障害物の 有無や道路の曲率の急激な変化などが運転歴などの経験と も関連しつつ，場合によっては大きなストレスを受けると 考えられるが，このような行為はそれ自体が事故に繋がる

* 富山大学 理工学研究部 生命・情報・システム学域 T930-8555 富山市五福 3190

Graduate School of Science and Engineering for Research, University of Toyama

3190, Gofuku, Toyama 930-8555, Japan

** (株) デンソー 基礎研究所

厂470-0111 愛知県日進市米野木町南山 500-1

Research Laboratories, DENSO Co.

500-1, Minamiyama, Komenoki-cho, Nisshin, Aichi 470-0111, Japan
可能性があるため, 実車で一般道を走行して評価するには 問題がある。そこで, 筆者らは, 運転席, 大型ディスプレ イとシミュレーションソフトなどで構成した乗用車の運転 模擬装置 (以下, ドライビングシミュレータ) を試作し, 標 識, 障害物などのイベントの有無や, 道路の曲率などの運 転タスクをコントロールできるソフトウエアを試作して, 自動車運転に起因するストレスや疲労を評価している。

しかし, 自動車の居住性能や操作性能が著しく向上した ことから, 数時間程度の運転では, 顕著なストレスや疲労 は観察されなくなってきた。最近では, 実車による数日間 にわたる長距離運転の疲労が報告されているが，このよう な人の連続モニタリングは容易ではない(4)。そこで, $110 \mathrm{~km} / \mathrm{h}$ を超える高速度運転で, 人の肉体的, 心理的影響を考察し ている研究もある ${ }^{(5)}$ 。筆者らも, ドライビングシミュレータ を用いて実車よりも多くの運転タスクを被検者に負荷する ことで，より短時間で人をストレス状態に至らせることが できるのではないかと考えている。

一方，心理計測の方法にも課題がある。心理計測とは, 生体が外界から加えられた刺激の量に対応する感覚量を, 
数值化して求めることを意味しており, 従来は脳波 (electroencephalogram, EEG) ${ }^{(6)}$ や脳血流量などの脳機能, 血 圧, 心拍数, 血流量や心電図 (electrocardiogram, ECG) など の循環機能, 呼吸数や呼吸量の呼吸機能や，発汗 ${ }^{(7)}$, 体温 ${ }^{(8)}$, 眼 球運動 ${ }^{(9)}$ などの物理計測が, 長い間指標として用いられてき た。脳血流量の分布は, 脳内の活動を 3 次元的に捉えるこ とができる優れた指標であるが，近赤外光を用いるので外 乱光を遮断できる設備が必要である。脳波は, 筋電位より もはるかに微弱な電位変動を計測する必要があるため, 被 検者が身動きできないように拘束しなければならない。こ のように，それぞれ制約条件があるために，随時性，即時 性，簡便性に優れた指標が無かった。

一方で, 血液, 間質液, 唾液, 尿などの生体液に含まれ るバイオマーカーを化学計測する方法が注目されている。 特に, 唾液をサンプル (検体) とすれば, 非侵襲で, 随時性, 簡便性に優れ，血液のように検体の採取自体がストレスに ならないというメリットがある。筆者らは, 唾液に含まれ る $\alpha$-アミラーゼ (以下, 唾液アミラーゼ) をバイオマーカー としたストレス研究を進めている。交感神経活性の増大が 主要因となって唾液アミラーゼが分泌されるので，唾液ア ミラーゼ活性は血液中のノルエピネフリン濃度の優れた指 標になると考えられている(10)(11)。最近では, 唾液アミラー ゼ活性をノルエピネフリン濃度の代わりに用い，交感神経 活性を評価する研究者も現れた (12)-(14)。

本研究では，これらの従来の課題に対処するために，ド ライビングシミュレータとバイオマーカーを用いた運転ス トレスの試験方法を提案する。運転に直接関与するタスク の量を任意にコントロールでき，かつアクセル，ブレーキ の使用頻度やコースからの横ずれ量などの物理量を計測で きるソフトウエアを試作した。また，本研究者らが試作した 携帯式の唾液アミラーゼ活性モニタを用い(15)(17), 非侵襲的に数 分おきにバイオマーカーを化学計測することで, 交感神経 活性を評価した。今回は, 比較のために眼球運動角度の物 理計測も行った。

本論文では，試作したドライビングシミュレータを用い， 健常成人女性 20 名による生体評価を通して, バイオマーカ 一による運転ストレス評価の可能性について考察する。

\section{2. 実験方法}

〈2·1〉 ドライビングシミュレータ＼cjkstart試作したドライ ビングシミュレータは, 運転装置, 大型ディスプレイ, シ ミュレーションソフト, 制御用コンピュータ, 計測用コン ピュータ，および顔画像記録装置から構成されている (図 1

(a))。

運転装置 $\left(110 \times 180 \times 125 \mathrm{~cm}^{3}\right)$ の座席やハンドルには, 排気量 2,000-3,000 cc クラスの普通乗用車 (トヨタ自動 車(株), クラウン) の部品を用いた (図 1 (b))。運転者は, 大 型ディスプレイ $\left(200 \times 170 \mathrm{~cm}^{2}\right)$ を見ながら，ハンドル，ア クセルとブレーキを操作して走行を模擬する。これ以外の 運転操作，例えばギアシフトやウインカーなどは設けなか

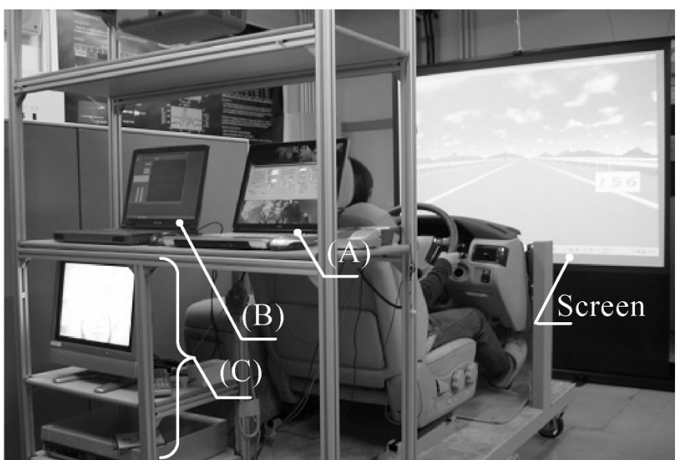

(a) External view of a motor-vehicle driving simulator

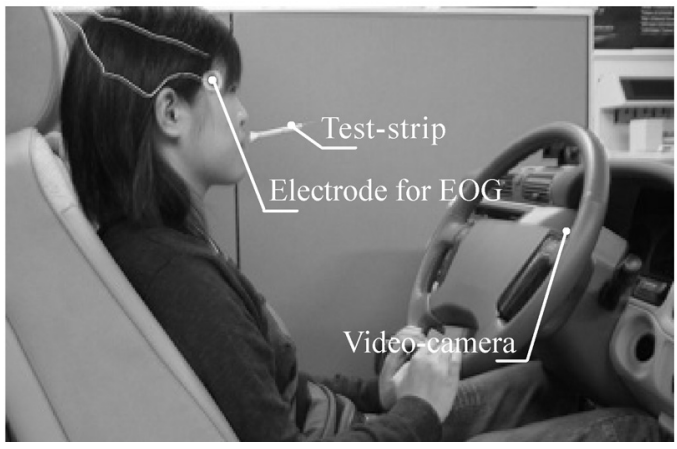

(b) Collecting of saliva

図 1 試作したドライビングシミュレータとそれを 用いた試験方法の様子; (A) 制御用コンピュータ,

(B) 計測用コンピュータ, (C) 顔画像記録装置

Fig. 1. External view of a fabricated motor-vehicle driving simulator and evaluation of driver stress ; (A) computer for control, (B) computer for measurement, (C) video-camera and recorder.

つた。

シミュレーションソフトは, 高低差がなく平坦で, 左右 両端に隔壁があり, 歩行者のいない片側 2 車線の自動車専 用道路の走行を模擬した (対向車線は模擬していない)。簡 略化のために, 並走車両, 対向車, トンネルや橋は模擬し なかった。走行コースは, 振幅と周期をパラメータとした サインカーブの組み合わせで変更できるようになってい る。今回は, 実車よりも多くの運転タスクを被検者に負荷 するという趣旨に照らし, 予備実験を繰り返して種々検討 した結果, 最終的には試行錯誤的に振幅 $18.2 \mathrm{~m}$, 周期 13.3 $\mathrm{s}$ のサインカーブ状で, 1 周の距離 $443 \mathrm{~m}$, 道路幅 $4.0 \mathrm{~m}$, コ ース幅 $12.0 \mathrm{~m}$ に設定した。走行速度は, 最大 $140 \mathrm{~km} / \mathrm{h}$ に 設定した。背景は, 青 (昼), オレンジ (夕方), 濃紺 (夜) の 3 種類から選択できる。イベントとしては, 左車線道路上 の障害物, 停止標識, 車線指示標識 (左へ, 右へ), 信号機 (青，赤) を表示できるようにした。

制御用コンピュータでは, シミュレーションソフトの駆 動と, 運転情報の記録を行った。運転情報としては, 走行 位置の横ずれ量, ハンドルの回転角, アクセル頻度, ブレ 一キ頻度，走行速度が記録できるが，今回は横ずれ量のみ を評価した。横ずれ量は, 2 つある走行車線の左車線の中央 
表 1 試験方法の評価に用いた被検者の背景

Table 1. Background of the 20 subjects used for a evaluation.

\begin{tabular}{ccccl}
\hline $\begin{array}{l}\text { Driving } \\
\text { frequency }\end{array}$ & Subject & Age & $\begin{array}{c}\text { Experience of driving } \\
\text { (month / year) }\end{array}$ & Driving \\
\hline \multirow{6}{*}{ Low } & $\mathrm{a}$ & 20 & $5 / 3$ & favor \\
& $\mathrm{b}$ & 21 & $8 / 1$ & favor \\
& $\mathrm{c}$ & 21 & $3 / 2$ & favor \\
& $\mathrm{d}$ & 23 & $7 / 2$ & favor \\
& $\mathrm{e}$ & 23 & $2 / 2$ & unfavor \\
& $\mathrm{f}$ & 20 & $2 / 2$ & unfavor \\
& $\mathrm{g}$ & 21 & $2 / 3$ & favor \\
& $\mathrm{h}$ & 21 & $10 / 0$ & favor \\
Mean $\pm \mathrm{SD}$ & $\mathrm{i}$ & 21 & $6 / 0$ & favor \\
& $\mathrm{j}$ & 21 & $7 / 2$ & moderate \\
\hline \multirow{6}{*}{ Normal } & $\mathrm{j}$ & $21.2 \pm 1.0$ & $1.84 \pm 0.94$ & \\
& $\mathrm{k}$ & 21 & $5 / 3$ & favor \\
& 1 & 21 & $2 / 3$ & favor \\
& $\mathrm{m}$ & 22 & $4 / 3$ & favor \\
& $\mathrm{n}$ & 22 & $8 / 3$ & moderate \\
& $\mathrm{p}$ & 20 & $7 / 0$ & favor \\
& $\mathrm{q}$ & 21 & $5 / 3$ & favor \\
& $\mathrm{r}$ & 21 & $2 / 3$ & favor \\
& $\mathrm{s}$ & 21 & $11 / 1$ & favor \\
& $\mathrm{t}$ & 23 & $11 / 1$ & favor \\
Mean \pm SD & & $20.3 \pm 4.4$ & $2.98 \pm 1.24$ & unfavor \\
\hline
\end{tabular}

を基準 $(0 \mathrm{~V})$, 中央線上を $0.5 \mathrm{~V}$ ，右車線の中央を $1.0 \mathrm{~V}$ と，左 壁 -1.0 - 右壁 $2.0 \mathrm{~V}$ までの範囲で測定した。

計測用コンピュータでは，運転者の生理量の物理計測と して，眼球運動角度を計測した。眼球運動角度は，右目の こめかみの下 $1 \mathrm{~cm}(+)$, 左目のこめかみの上 $1 \mathrm{~cm}(-)$, 額 $($ ア 一ス) の 3 ケ所に生体用電極 (Ambu Inc., デンマーク)を設 置し, 眼球電位を用いた眼球運動記録法 (electro-oculography, EOG) ${ }^{(18)}$ により測定した (図 1 (b))。正 面を見たときを基準 $(0 \mathrm{~V})$ とし, 左右 \pm 30 度を $\pm 0.5 \mathrm{~V}$ と して表示した。

運転者の顔画像は，カラービデオカメラ (CCD-MC100, ソニー(株)) で撮影し，ビデオレコーダー (DV-RW 100，シ ヤープ (株)) で録画した。

$\langle 2 \cdot 2\rangle$ 唾液アミラーゼ活性 運転者の交感神経活性 を評価するため，唾液アミラーゼ活性の測定を行った。測 定には，筆者らが試作した携帯式の唾液アミラーゼ活性測 定器を用いた ${ }^{(13)(14)}$ 。この装置は，アミラーゼの基質として Gal-G2-CNP を含浸した試験紙を用いた。唾液の $\mathrm{pH}$ と温度 の影響を補正するための検量線が記憶されており，自動的 に $37^{\circ} \mathrm{C}$, pH 6.5 の結果が表示される。交感神経モニタは, 試験紙を内蔵した使い捨て式のテストストリップと本体 $\left(110 \times 100 \times 40 \mathrm{~mm}^{3}, 350 \mathrm{~g}\right)$ で構成した。本測定器は, テス トストリップでわずか $30 \mu \mathrm{l}$ の唾液を約 $30 \mathrm{~s}$ かけて採取 したあと, 試験紙の発色濃度変化の測定に $30 \mathrm{~s}$ が必要であ り，計 1 分ほどで唾液アミラーゼ活性を分析できる。

$\langle 2 \cdot 3\rangle$ 被検者被検者は，口腔内疾患が認められな い健常な成人女性 20 名 (年齢 $21.25 \pm 0.91$ 歳, mean $\pm \mathrm{SD}$ ) で，運転頻度が週 2 回以上の 10 名 (運転頻度がノーマルな グループ，Group normal) と，運転頻度が週 1 回以下の 10 名（運転頻度が低いグループ，Group low）の計 20 名を用い た (表 1)。本研究のプロトコールは, 富山大学倫理委員会

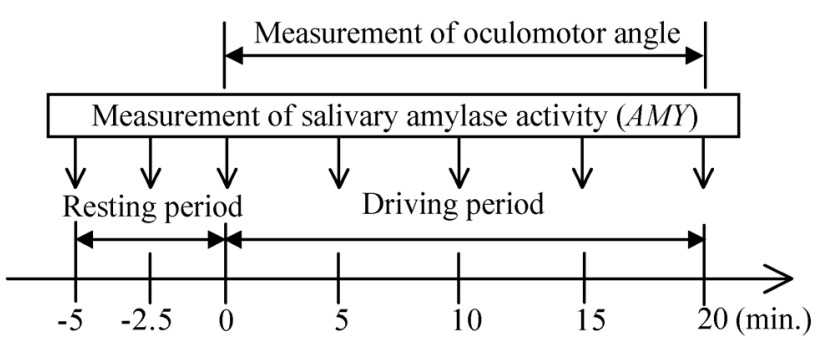

図 2 ドライビンシミュレータを用いた試験方法の 評価プロトコール

Fig. 2. Protocol of a evaluation using a motor-vehicle driving simulator.

(富山市) に諮り, その承認を得た。被検者には, 口頭と書 面の双方により研究の趣旨, プロトコール，危険性につい て十分に説明し，書面により本人から直接同意を得た。

〈2・4〉＼cjkstart測定プロトコール＼cjkstart測定プロトコールは，安 静時と模擬運転の 2 つの期間から構成し，模擬運転開始時 を 0 分とした。まず, 被検者へ眼球運動角度の測定用電極 を装着した。次に, 被検者に 5 分間座位を取らせ, $-5,-2.5$, 0 分の安静時の唾液アミラーゼ活性を分析し, 最も低い唾液 アミラーゼ活性を安静時值とした。その後, ドライビング シミュレータによる模擬運転を 20 分間行わせ, 唾液アミラ 一ゼ活性の分析を 5 分間隔で行った。唾液アミラーゼ活性 の日内変動の影響を少なくするため, 測定は 9:00〜 12:00 a.m. の間に実施し, 室内温度を $25^{\circ} \mathrm{C}$ 設定した。測定開始 前 1 時間は, 食事, タバコ, コーヒーなどの嗜好品の摂取 は控えさせ, 測定直前に歯磨きを行わせて口腔内を洗浄さ せた。唾液アミラーゼ活性の経時変化は, 対数を取ること で正規化して示した。

被検者にできるだけ多くの運転タスクを与えるために， シミュレーションソフトの設定は, 背景色を視界が悪いオ レンジ (夕方) とし，かつ 1 分毎にイベントが発生するよう に設定した。被検者には, $120 \mathrm{~km} / \mathrm{h}$ を目標值として走行さ せ，できるだけ車線の中央を走行するように指示した。

被検者の運転状況の把握のために, 走行位置の横ずれ量 (以下，横ずれ量) と眼球運動角度の測定を行った。運転開 始 $(0$ 分) と同時に測定を開始し, サンプリング周波数 10 $\mathrm{Hz}$ (0.1 秒間隔) で運転終了まで 20 分間継続した。横ずれ量 と眼球運動角度は, 5 分毎の積分值を算出して示した。最後 に, 横ずれ量と眼球運動角度に関し, 時間差を独立変数, 測定值を従属変数として 2 元配置分散分析した。

\section{3. 結果}

〈3.1〉 横ずれ量と眼球運動角度 横ずれ量の 5 分毎 の積分值は, Group normal が $101.3-340.0$ (平均 171.5) V·s (364.2-1234.3 m·s に相当), Group low が $100.3-353.8$ (平 均 198.0$) \mathrm{V} \cdot \mathrm{s}(367.7-1280.4 \mathrm{~m} \cdot \mathrm{s}$ に相当) の範囲にあった (図 3)。眼球運動角度の 5 分毎の積分值は, Group normal が 175.4 - 398.8 (平均 219.8) V·s, Group low が 142.6-368.9 (平 均 225.8$) \mathrm{V} \cdot \mathrm{s}$ の範囲にあった。眼球運動角度が大きいとき 
O: Deviation value $\Delta$ : Oculomotor angle

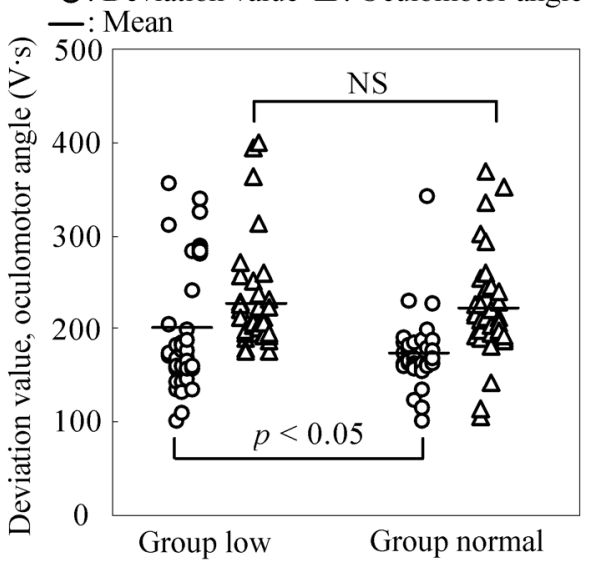

図 3 横ずれ量と眼球運動角度の運転頻度による比較 Fig. 3. Comparison of deviation value from the driving course (deviation value) and oculomotor angle by the driving frequency.

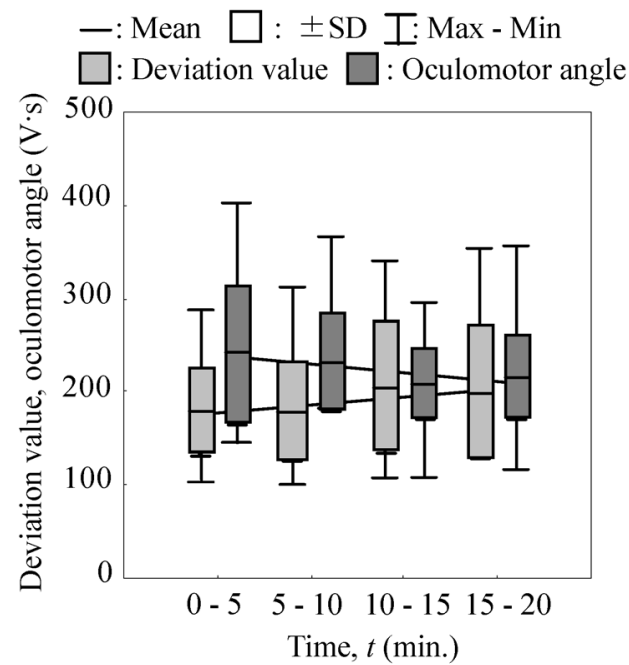

図 4 横ずれ量と眼球運動角度の経時変化 (横ずれ量 : 傾き $a=12$, 切片 $b=230, R^{2}=0.027$, 眼球運動角度 :

$$
a=-8.85 \text {, 切片 } b=246.5, \quad R^{2}=0.035 \text { ) }
$$

Fig. 4. Time-course changes of deviation value from the driving course (deviation value) and oculomotor angle. (deviation value : slope $a=12, y$-intercept $b=230, R^{2}=$ 0.027 , oculomotor angle : slope $a=-8.85, y$-intercept $b=$ $\left.246.5, R^{2}=0.035\right)$

には，顔画像記録にも頻繁な眼球運動が記録されており， 本計測の妥当性が確認された。1 標本 $t$ 検定を行ったところ, 横ずれ量では，有意確率 $p<0.05$ となり，運転頻度により 有意差が観察され, 運転頻度が高いほうが横ずれ量が小さくな る傾向にあった。しかし, 眼球運動角度では, $p>0.05$ となり, 有意差は観察されなかった。

また，両值の経時変化を直線回帰分析したところ，横ず れ量は傾き $a=12$, 切片 $b=230, R^{2}=0.027$ で微増し, 眼 球運動角度は傾き $a=-8.85$, 切片 $b=246.5, R^{2}=0.035$ で
表 2 安静座位と模擬運転の唾液アミラーゼ活性

$$
(A M Y) \text { の比較 }
$$

Table 2. Comparison of the salivary amylase activity (AMY) between resting and driving periods.

\begin{tabular}{|c|c|c|c|}
\hline \multirow[t]{2}{*}{ Subject } & $\begin{array}{l}A M Y \text { of resting } \\
\text { period }(\mathrm{kU} / \mathrm{L})\end{array}$ & $\begin{array}{l}A M Y \text { of driving period } \\
(\mathrm{kU} / \mathrm{L})\end{array}$ & \multirow{2}{*}{$\begin{array}{c}\text { Increasing } \\
\text { rate }(\%)\end{array}$} \\
\hline & Mean \pm SD & Mean \pm SD & \\
\hline $\mathrm{a}$ & 22 & $40.3 \pm 7.0$ & 83.0 \\
\hline b & 12 & $14.3 \pm 2.1$ & 18.8 \\
\hline $\mathrm{c}$ & 6 & $8.5 \pm 1.3$ & 41.7 \\
\hline d & 15 & $15.3 \pm 1.7$ & 1.7 \\
\hline e & 9 & $10.8 \pm 1.3$ & 19.4 \\
\hline $\mathrm{f}$ & 11 & $30.0 \pm 13.9$ & 172.7 \\
\hline g & 11 & $13.5 \pm 3.7$ & 22.7 \\
\hline $\mathrm{h}$ & 17 & $30.8 \pm 8.4$ & 80.9 \\
\hline $\mathrm{i}$ & 12 & $14.0 \pm 1.4$ & 16.7 \\
\hline $\mathrm{j}$ & 15 & $13.9 \pm 1.3$ & 28.3 \\
\hline Mean \pm SD & $13.0 \pm 2.5$ & $19.4 \pm 11.0$ & 48.6 \\
\hline \multicolumn{4}{|c|}{ (b) Group normal } \\
\hline \multirow[t]{2}{*}{ Subject } & $\begin{array}{l}A M Y \text { of resting } \\
\text { period }(\mathrm{kU} / \mathrm{L})\end{array}$ & $\begin{array}{l}A M Y \text { of driving } \\
\text { period }(\mathrm{kU} / \mathrm{L})\end{array}$ & \multirow{2}{*}{$\begin{array}{c}\text { Increasing } \\
\text { rate }(\%)\end{array}$} \\
\hline & Mean \pm SD & Mean \pm SD & \\
\hline $\mathrm{k}$ & 27 & $53.3 \pm 11.6$ & 97.2 \\
\hline 1 & 6 & $12.3 \pm 3.4$ & 104.2 \\
\hline $\mathrm{m}$ & 18 & $16.3 \pm 5.6$ & -9.7 \\
\hline $\mathrm{n}$ & 12 & $15.3 \pm 4.5$ & 27.1 \\
\hline o & 24 & $27.8 \pm 1.5$ & 15.6 \\
\hline $\mathrm{p}$ & 7 & $11.0 \pm 1.7$ & 57.1 \\
\hline$q$ & 9 & $21.3 \pm 5.1$ & 136.1 \\
\hline $\mathrm{r}$ & 6 & $5.8 \pm 1.0$ & -4.2 \\
\hline $\mathrm{s}$ & 14 & $17.8 \pm 1.5$ & 26.8 \\
\hline $\mathrm{t}$ & 12 & $14.3 \pm 4.0$ & 18.8 \\
\hline Mean \pm SD & $13.5 \pm 4.0$ & $19.7 \pm 13.6$ & 46.9 \\
\hline
\end{tabular}

(a) Group low

微減する傾向が観察された (図 4)。しかし, $R^{2}$ は小さく, 顕著な変化は観察されなかった。また, 2 元配置分散分析で は, 横ずれ量と眼球運動角度のいずれも $P>0.05$ となり, 有意差としては観察されなかった。

〈3·2〉唾液アミラーゼ活性安静時座位の唾液アミ ラーゼ活性は，全被検者 20 名で $13.2 \pm 6.0 \mathrm{kU} / 1$ (mean士 $\mathrm{SD}), \mathrm{CV}=37.0 \%$ であった。唾液アミラーゼ活性の模擬運 転 20 分間の平均值と安静時座位に対する増加率は, Group normal が $19.7 \pm 13.6 \mathrm{kU} / 1,46.9 \%$, Group low が $19.4 \pm 11.0$ $\mathrm{kU} / 1,48.6 \%$ と何れも $50 \%$ 近く増加したが， 2 群に大差はな かった (表 2)。

安静時座位に対する模擬運転の唾液アミラーゼ活性の増 加率は，運転頻度に関係なく，40\%以下と $60 \%$ 以上の 2 群 に分類することができた (図 5)。

全被検者において, 唾液アミラーゼ活性の安静時值と, 模擬運転における 4 回の測定結果の対比をまとめて示した (図 6, $n=78$ )。直線回㷌分析したところ, 傾き $a=1.62$, 切 片 $b=-2.13, R^{2}=0.60$ となった。個々のデータポイントで は, $\mathrm{a}<1$ の值が全体の $9 \%$ 観察された。

\section{4. 考察}

〈4·1〉横ずれ量と眼球運動角度 今回の被検者は, 免許所得から平均で 2 年 5 ケ月しか経っておらず, 運転経 験としてはまだ浅かったが，運転頻度が週 2 回以上あり， この経験の差が横ずれ量には反映され, 運転頻度が高いほ 

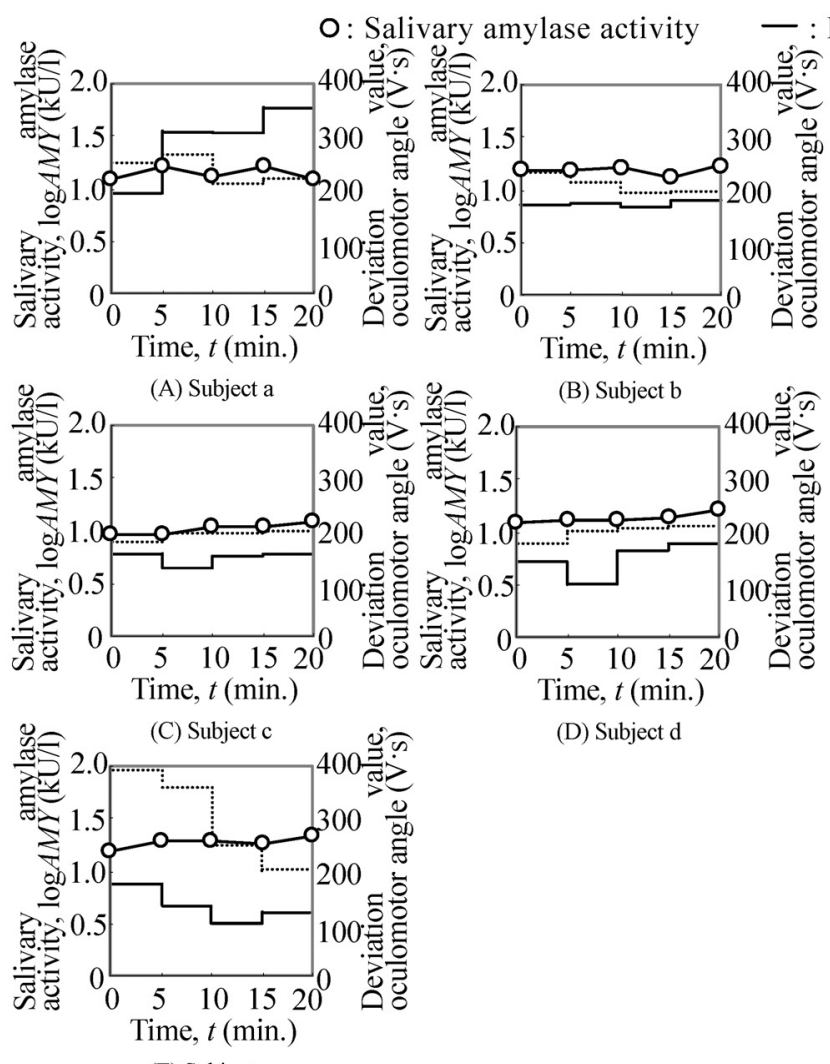

(D) Subject d

(E) Subject e

(i) Increasing rate of the salivary amylase activity is under $40 \%$ (reference is $0 \mathrm{~min}$.)
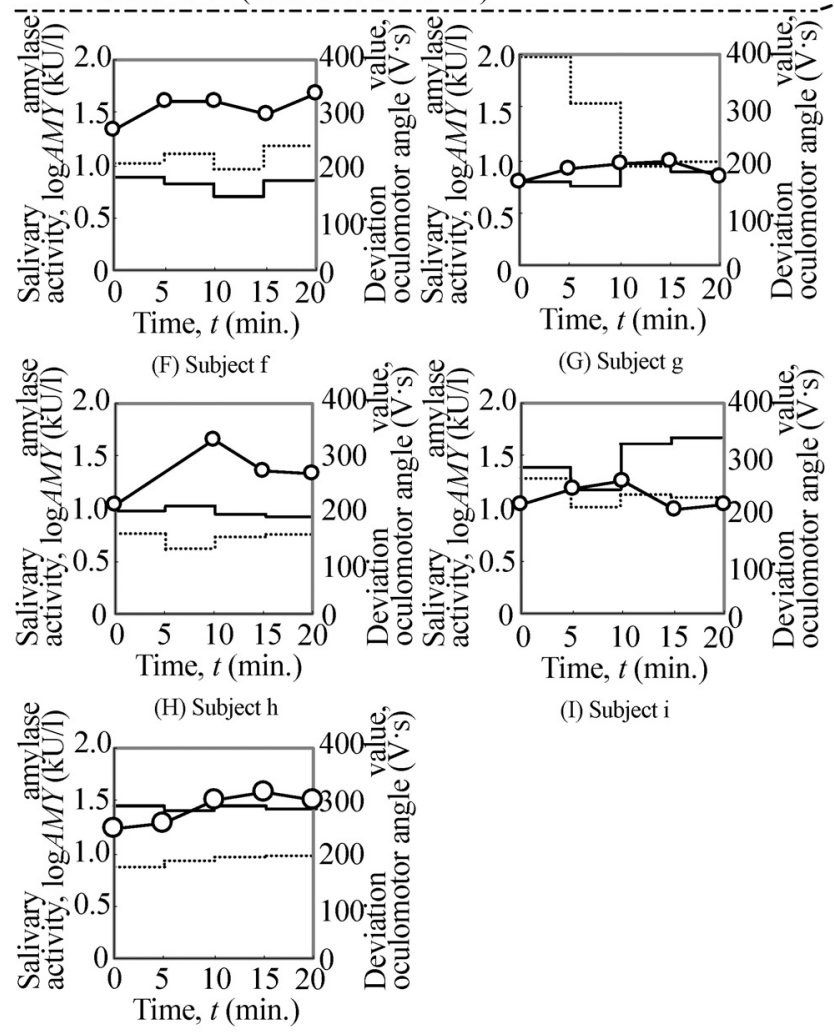

(I) Subject $\mathrm{i}$

(J) Subject $\mathrm{j}$

(ii) Increasing rate of the salivary amylase activity is

over $60 \%$ (reference is $0 \mathrm{~min}$.)

(I) Group low

図 5 増加率 $40 \%$ 以下と $60 \%$ 以上の 2 群に分類された唾液アミラーゼ活性，横ずれ量と眼球運動角度の経時変化

Fig. 5. Time-course changes of the saliva amylase activity, deviation value and oculomotor angle. 


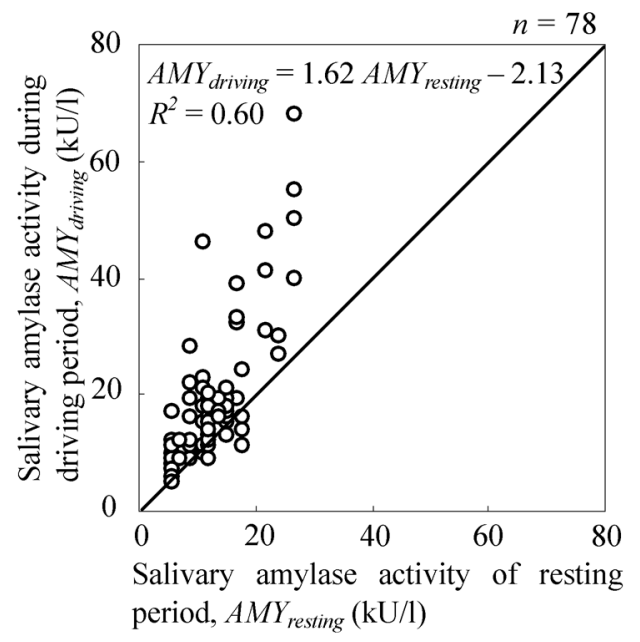

図 6 模擬運転と安静座位の唾液アミラーゼ活性の比較

Fig. 6. Comparison of salivary amylase activity between driving and resting periods.

うが横ずれ量を低減させたのではないかと考えられ，統計 的に有意差として判別できる程度であった。横ずれ量の経 時的な変化では, 統計的な有意差は観察されなかったが, 時間とともに微増し，一過性ではあるが運転者の疲労を反 映している可能性も示唆された。

しかし，実車で一般道を走行したわけではないので，歩 行者や他の車に注意を払う必要はなく, そのため運転頻度 の差が眼球運動角度には反映されなかったと考えられた。 すなわち，ドライビングシミュレータを用い，安全性が確 保されていることを被検者が十分理解できる試験方法にお いても，横ずれ量などの運転情報を測定することは意味が あると考えられた。また, 並走車両や対向車も模擬すれば, 眼球運動角度の測定も意味を持つのではないかと考えられ る。

〈4·2〉 唾液アミラーゼ活性横ずれ量と同様に, 唾 液アミラーゼ活性においても運転頻度による明確な差異は 観察されなかった。このことから，運転歷が $2-3$ 年と比 較的浅い被検者においては, 運転頻度が週 2 回以上, 週 1 回以下といった詳細な条件まで結果には影響しないといえ る。本運転ストレスの試験方法は, その程度の許容度を有 していると考えられた。

一方, 被検者の日常生活における運転頻度 (Group low と Group normal) に関係なく，模擬運転というストレッサーに 対して唾液アミラーゼ活性の増加率が $40 \%$ 以下と $60 \%$ 以上の 2 群に分類できた。これは, 同一の運転刺激に対し, 感受性が高い被検者群と低い被検者群が存在する可能性を 示唆している。このような交感神経活性の増加率は, 被検 者のストレス而性，性格や記憶を反映しているのではない かと推定された。すなわち，運転ストレスを評価する場合 には，無作為に一人でも多くの被検者を集めるだけでは不 十分で, 被検者の背景を十分考慮に入れることも重要と考 えられた。

安静時値と模擬運転時の唾液アミラーゼ活性の対比にお
いて, 全被検者のデータから一次近似直線を求めたところ, 傾き $a=1.62$ と $\mathrm{a}>1$ が示され, 上昇が認められた。本研 究で提案した運転ストレスの試験方法によって, 安静時座 位の唾液アミラーゼ活性を基準として模擬運転による急性 の交感神経活性の変動を経時的に観察することは, 自動車 運転によるヒト・ストレスの評価に有効であると考えられ た。

\section{5. 結 論}

ドライビングシミュレータを用い, 実車に比べてより多 くの運転タスクを被検者に負荷することで, わずか 20 分間 ほどで, かつ被検者を危険にさらすことなく, 運転ストレ スを与える実験を行った。

特に, 唾液アミラーゼ活性のように唾液から非侵襲的に 分析でき, 随時性, 即時性, 簡便性に優れたバイオマーカ 一を指標とすることによって, 測定のために被検者を拘束 することなく, 交感神経活性を頻繁に計測可能となること を示すことができた。

ドライビングシミュレータをそのまま実車の代わりに用 いることはできないが，この運転ストレスの試験方法は， 今までプロテストドライバーの主観評価を中心に行われて きた自動車開発において, 安全性を確保することによって 一般消費者を対象として評価可能とするとともに, 自動車 の居住性能や操作性能のより一層の改善や, 人的エラーに 起因寸る危険の低減に有用であると考えられる。

今後は, 性差, 年齢, 長期の運転経験, 走行コースのパ ターンなど, 様々な条件が与える影響について考察してい きたい。

\section{謝 辞}

本研究の一部は, 平成 17 年度科学研究費補助金 (基盤研 究 (C), 課題番号 17500350) によって行われた。

(平成 17 年 12 月 2 日受付, 平成 18 年 5 月 22 日再受付)

\section{文献}

(1) K. L. L. Saroj and A. Craig : "Driving fatigue : Electroencephalography and psychological assessment", Psychophysiology, Vol.39, pp.313-321 (2002)

(2) P. C. Morrow and M. R. Crum : "Antecedents of fatigue, close calls, and crashes among commercial motor-vehicle drivers", J. of Safety Research, Vol.35, pp.59-69 (2004)

( 3 ) S. M. Belz, G. S. Robinson, and J. G. Casali : "Temporal separation and self-rating of alertness as indicators of driver fatigue in commercial motor vehicle operators", Human Factors, Vol.46, pp.154-169 (2004)

(4) J. K. Sluiter, A. J. van der Beek, and M. H. Frings-Dresen : "Work stress and recovery measured by urin catecholamines and cortisol excretion in long distance coach drivers", Occupatical and Evironment Medicine, Vol.55, No.6, pp.407-413 (1998-6)

(5) M. Uchikune : "Physiological and Psychological Effects of High Speed Driving on Young Male Volunteers", J. of Occupational Health, Vol.44, pp.203-206 (2002)

(6) T. Yoshida and T. Iwaki : "The study of early emotion processing in the frontal area using a two-dipole source model", Jan. Psychological Res., Vol.42, pp.54-68 (2000) 
( 7 ) K. E. Hagbarth, R. G. Hallin, A. Hongell, H. E. Torebjörk, and B. G. Wallin : "General characteristics of sympathetic activity in human skin nerves”, Acta Physiologica Scandinavica, Vol.84, No.2, pp.164-176, (1972-2)

( 8 ) S. M. Fortney and N. B. Vroman : "Exercise, performance and temperature control: temperature regulation during exercise and implications for sports performance and training", Sports Medicine, Vol.2, pp.8-20 (1985)

(9) W. W. Wierwille : "Physiological measures of aircrew mental workload", Human Factors, Vol.21, No.5, pp.575-593 (1979-5)

(10) D. R. Morse, G. R. Schacterle, M. LawrenceFurst, J. V. Esposito, and M Zaydenburg : "Stress, relaxation and saliva: relationship to dental caries and its prevention, with a literature review", Annals of dentistry, Vol.42, pp.47-55 (1983)

(11) R. T. Chatterton, K. M. Vogelsong, Y. Lu, A. B. Ellman, and G. A. Hudgens : "Salivary $\alpha$-amylase as a measure of endogenous adrenergic activity", Clinical Physiol, Vol.16, pp.433 - 448 (1996)

(12) P. D. Skosnik, R. T. Chatterton, T. Swisher, and S. Park : "Modulation of attentional inhibition by norepinephrine and cortisol after psychological stress", Int. J. Psychophysiology, Vol.36, pp.59 - 68 (2000)

(13) W. E. Morrison, E. C. Haas, D. H. Shaffner, E. S. Garrett, and J. C. Fackler : "Noise, stress, and annoyance in a pediatric intensive care unit", Crit. Care Med., Vol.31, No.1, pp.113-119 (2003-1)

(14) N. Rohleder, U. M. Nater, J. M. Wolf, U. Ehlert, and C. Kirschbaum : "Psychosocial stress-induced activation of salivary alpha-amylase", Ann. N.Y. Acad. Sci., Vol.1032, pp.258-263 (2004)

(15) M. Yamaguchi, T. Kanemori, M. Kanemaru, Y. Mizuno, and H. Yosida : "Test-Strip-Type Salivary Amylase Activity Monitor and Its Evaluation", Sensors and Materials, Vol.15, No.5, pp.283-294 (2003-5)

(16) N. Takai, M. Yamaguchi, T. Aragaki, K. Eto, K. Uchihashi, and Y. Nishikawa : "Effect of psychological stress on the salivary coltisol and amylase levels in healthy young adults", Archives of Oral Biology, Vol.49, No.12, pp.963-968 (2004-12)

(17) M. Yamaguchi, M. Deguchi, J. Wakasugi, S. Ono, N. Takai, T. Higashi, and Y. Mizuno : "Hand-held monitor of sympathetic nervous system using salivary amylase activity and its validation by driver fatigue assessment", Biosensors \& Bioelectronics, Vol.21, No.7, pp.1007-1014 (2006-7)

(18) M. F. Marmor and E. Zrenner : "Standard for clinical electrooculography", Springer Science and Business Media, Vol.85, No.2, pp.115-124 (1993-2)

出口満生 (非会員) 1981 年 3 月 7 日生。 2004 年 3 月富 山大学工学部物質生命システム工学科卒業。現 在, 富山大学理工学研究科博士前期課程物質生 命システム専攻 2 年。唾液アミラーゼ活性を用 いたストレス測定技術を研究。

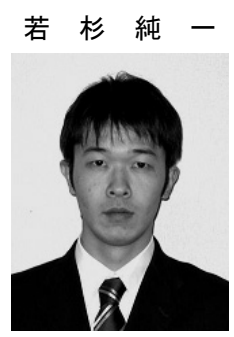

（非会員） 1982 年 7 月 19 日生。 2003 年 3 月富 山大学工学部物質生命システム工学科卒業。現 在, 富山大学理工学研究科博士前期課程物質生 命システム専攻 1 年。喠液アミラーゼ活性を用 いたストレス測定技術を研究。

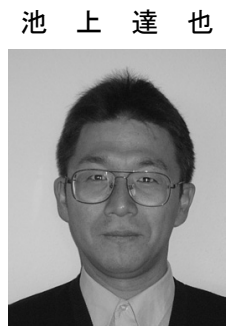

（非会員） 1967 年 7 月 2 日生。1991 年 3 月名 古屋大学工学部応用物理学科卒業。同年(㐺デン ソー入社, 現在, デンソー基礎研究所にてドラ イバーの状態検出技術を研究。

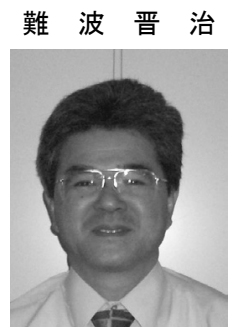

（非会員） 1954 年 9 月 11 日生。1979 年 3 月神 戸大学工学部生産機械工学科修士課程修了。同 年(株デンソー入社。エンジン研究, 光センシン グ研究を経て, 現在, デンソー基礎研究所にて 生体信号研究に従事。

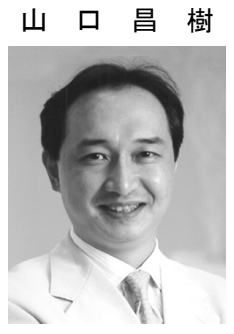

（正員）1987 年信州大学大学院修士課程修了。 同年ブラザー工業㑣入社。1994 年信州大学大学 院博士後期課程修了(博士)。1995 年東京農工大 学助手, 1999 年富山大学助教授, 現在に至る。 2001 年日経 BP 技術賞受賞。2004 年(有)バイオ情 報研究所を創業。生命計測工学の研究に従事。 